\title{
PERBEDAAN LATIHAN HIGH INTENSITY GROUND WALKING DAN LATIHAN STATIC BICYCLE TERHADAP KAPASITAS LATIHAN PADA PENDERITA PPOM
}

\author{
Setiawan, Nur Basuki \\ Kementerian Kesehatan Politeknik Kesehatan Surakarta Jurusan Keperawatan
}

\begin{abstract}
High Intensity Ground Walking, Static Bicycle exercise, exercise capacity, the 6-minutes walking test, chronic obstructive pulmonary disease (COPD). This study aimed to compare the benefits between High Intensity Ground Walking exercise and Static Bicycle exercise on exercise capacity in patients with chronic obstructive pulmonary disease (COPD). This research is a quasi-experimental study design with two groups pre and post test design. The subjects were all patients COPD with moderate and severe degree in The Special hospital of Pulmonary dr. Ario Wirawan Salatiga, that meet the inclusion and exclusion criteria. The data was collected directly by assessing the results of the six-minute walk test before and after the treatments. Data collected were analyzed using SPSS 11.5. The different test within groups measured with Wilcoxon test, and for between groups measured wirh Mann Whitney test. The significance level was set on 0.05. Results and Conclusion (1) High Intensity Ground Walking exercises improve exercise capacity in patients with COPD $(p=0.005)$, (2) Static Bicycle training program improve exercise capacity of patients with COPD $(p=0.005)$, (3) There is no difference between High Intensity Ground Walking Exercise and Static Bicycle training in improving exercise capacity in patients with COPD $(p=0.970)$.
\end{abstract}

Keywords: High Intensity Ground Walking, Static Bicycle exercise, exercise capacity, the 6-minutes walking test, chronic obstructive pulmonary disease (COPD).

Abstrak: High Intensity Ground Walking, latihan Static Bicycle, kapasitas latihan, tes jalan 6 menit, penyakit paru obstruktif menahun (PPOM). Penelitian ini bertujuan untuk membandingkan manfaat latihan High Intensity Ground Walking dengan latihan Static Bicycle terhadap kapasitas latihan pada penderita PPOM. Penelitian ini adalah penelitian eksperimental semu dengan desain two groups pre and post test design. Subyek penelitian adalah semua pasien PPOM dengan derajad sedang dan berat di RS. Paru dr. Ario Wirawan Salatiga yang memenuhi kriteria inklusi dan eksklusi. Hasil Pengumpulan data dilakukan secara langsung dengan menilai hasil tes jalan enam menit sebelum dan sesudah perlakuan.Data yang dikumpulkan akan dianalisis dengan menggunakan bantuan software SPSS 11,5. Uji beda dalam kelompok digunakan Wilcoxon test sedang untuk antar kelompok menggunakan Mann Whitney test. Tingkat kemaknaan ditetapkan 0,05. Hasil dan Kesimpulan (1) Program latihan High Intensity Ground Walking meningkatkan kapasitas latihan pada penderita PPOM $(\mathrm{p}=0,005)$, (2) Program latihan Static Bicycle meningkatkan kapasitas latihan penderita PPOM $(\mathrm{p}=0,005)$, (3) Tidak ada perbedaan atau 
sama baik antara program latihan High Intensity Ground Walking dengan Latihan Static Bicycle dalam meningkatkan kapasitas latihan pada penderita PPOM ( $\mathrm{p}=0,970)$.

Kata Kunci: High Intensity Ground Walking, latihan Static Bicycle, kapasitas latihan, tes jalan 6 menit, penyakit paru obstruktif menahun (PPOM).

\section{PENDAHULUAN}

Tingkat polusi udara di Indonesia dari tahun ke tahun semakin memprihatinkan. Bahkan salah satu studi melaporkan bahwa Indonesia menjadi negara dengan tingkat polusi udara tertinggi ketiga di dunia. World Bank juga menempatkan Jakarta menjadi salah satu kota dengan kadar polutan/partikulat tertinggi setelah Beijing, New Delhi dan Mexico City. Tingginya tingkat polusi ini akan berdampak pada semakin tingginya prevalensi penyakit paru termasuk Penyakit Paru Obstruktif Menahun (PPOM). PPOM adalah merupakan penyakit pada sistem pernapasan dimana saluran pernapasan akan menyempit sehingga akan menghambat keluar masuknya udara ke paru yang akan menyebabkan keluhan sesak napas. Prevalensi PPOM senantiasa meningkat dari waktu ke waktu. Di seluruh dunia pada tahun 2004 terdapat lebih dari 60 juta orang menderita PPOM (WHO, 2012).

Penurunan kapasitas latihan adalah merupakan problem utama yang dikeluhkan oleh penderita PPOM yang utamanya disebabkan oleh sesak pada saat melakukan aktivitas. Penurunan kapasitas latihan pada pasien PPOM bukan hanya akibat dari adanya kelainan obstruksi saluran nafas pada parunya saja tetapi juga akibat pengaruh beberapa faktor, salah satunya adalah penurunan fungsi otot skeletal. Adanya disfungsi otot skeletal dapat menyebabkan penurunan kualitas hidup penderita karena akan membatasi kapasitas latihan dari pasien PPOM (Celli, 2004).

Dewasa ini telah berkembang berbagai macam jenis latihan seiring dengan semakin meningkatnya prevalensi dari penderita PPOM. Dengan adanya berbagai jenis latihan tersebut kiranya perlu dievaluasi manfaat dari berbagai macam jenis latihan tersebut. Latihan dengan menggunakan static bicycle akhir akhir ini menjadi salah satu jenis latihan yang banyak di kembangkan di berbagai rumah sakit sebagai dampak dari kemajuan teknologi yang ada. Belum banyak penelitian yang meneliti tentang manfaat latihan dengan menggunakan static bicycle ini. Disisi lain high intensity ground walking juga merupakan suatu jenis latihan yang banyak digunakan pada manajemen penderita PPOM. Jenis latihan ini juga belum banyak meneliti (Leung et al, 2010).

\section{METODE PENELITIAN}

Penelitian ini adalah merupakan penelitian eksperimen semu dengan desain two groups pre and post test design yang bertujuan untuk mengetahui perbedaan manfaat program latihan high intensity ground walking dan static bicycle dalam meningkatkan kapasitas latihan pasien PPOM. Adapun skema penelitiannya dapat digambarkan sebagai berikut. 


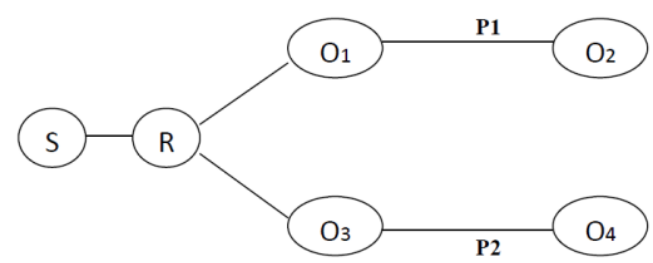

Gambar. 4.1 Rancangan penelitian

$\mathrm{S}=$ Subyek penelitian

$\mathrm{R}=$ Randomisasi

P1 = Program latihan high intensity ground walking

P2 = Program latihan static bicycle

$\mathrm{O} 1=$ Pre tes kelompok program latihan high intensity ground walking

$\mathrm{O} 2=$ Post tes kelompok program latihan high intensity ground walking

$\mathrm{O} 3=$ Pre tes kelompok program latihan static bicycle

$\mathrm{O} 4=$ Post tes kelompok program latihan static bicycle

Penelitian ini dilaksanakan RS Paru dr. Ario Wirawan Salatiga. Pegambilan data ini dilaksanakan selama tiga bulan, mulai bulan April sampai dengan Juni 2015.

Subyek penelitian adalah semua pasien PPOM yang berobat ke RS Paru dr. Ario Wirawan Salatiga yang memenuhi kriteria inklusi dan eksklusi. Kriteria inklusi yang ditetapkan dalampenelitian ini adalah : (1) PPOM derajad sedang dan berat, (2) umur 25 sd 70 tahun, (3) nilai FEV1 $<60 \%$, (4) ada penurunan toleransi aktivitas dengan hasil pemeriksaan tes jalan 6 menit < 300 meter, (5) bersedia mengikuti penelitian ini. Kriteria eksklusi dalam penelitian ini adalah: (1) memiliki penyakit penyerta yaitu jantung, gagal ginjal, DM yang tidak terkontrol, hipertensi berat, (2) jalan menggunakan alat bantu, (3) mempunyai gangguan muskuloskeletal dan neurumuskuler pada ekstremitas bawah. Dalam penelitian ini di kategorikan dalam kriteria drop out bila tidak mengikuti latihan lebih dari 3 kali.
Variabel dalam penelitian ini adalah: (1) Variabel bebas: program latihan high intensity ground walking dan latihan static bicycle, (2) Variabel terikat : kapasitas latihan.

Peralatan yang digunakan untuk mengukur kapasitas latihan pasien adalah alat alat yang digunakan untuk mengukur tes berjalan enam menit yang terdiri dari: tensimeter, pulse oxymeter, stop watch dan blanko pencatatan pelaksanaan penelitian. Semua peralatan yang digunakan akan dilakukan uji kalibrasi untuk menentukan ketepatannya.

Sebelum melaksanakan penelitian terlebih dahulu mengajukan permohonan ijin kepada Direktur RS Paru dr. Ario Wirawan Salatiga. Setelah mendapatkan ijin, langkah selanjutnya ialah melakukan perekrutan terhadap tenaga fisioterapis yang ada di RS Paru dr. Ario Wirawan Salatiga untuk menjadi anggota tim dalam penelitian ini. Mereka terbagi dalam petugas yang melakukan pengukuran awal dan akhir, serta petugas yang memberikan program latihan high intensity ground walking dan latihan static bicycle.

Semua pasien yang dirujuk ke bagian fisioterapi untuk mengikuti program rehabilitasi paru sederhana akan dilakukan pemeriksaan untuk mengetahui apakah penderita masuk dalam kriteria inklusi dan eksklusi. Selanjutnya bila mereka setuju maka akan dialokasikan ke dalam kelompok I yaitu latihan high intensity ground walking atau kelompok II yaitu latihan static bicycle secara acak.

Selanjutnya, subyek penelitian yang sudah didata dilakukan pengukuran 
awal kapasitas latihannya menggunakan tes jalan enam menit.

Kelompok satu mendapatkan perlakuan berupa satu set program dimana penderita diminta untuk berjalan dengan kecepatan $65 \%$ dari kecepatan maksimalnya selama 20 menit. Intensitas latihan akan ditingkatkan secara progressive tergantung respon kardiorespirasi dari masing masing pasien. Latihan ini diberikan dua kali seminggu selama 6 minggu.

Kelompok dua mendapatkan perlakuan berupa satu set program rehabilitasi paru, dimana penderita diminta untuk mengayuh sepeda statis dengan intensitas $65 \%$ dari beban maksimalnya selama 20 menit, kemudian ditingkatkan secara progresif sesuai dengan kemampuan kardiorespirasinya. Latihan ini diberikan dua kali seminggu selama 6 minggu

Semua subyek yang telah menyelesaikan program rehabilitasi paru sederhanan akan dilakukan pengukuran akhir kemampuan fungsional dengan menggunakan tes jalan enam menit. Fisioterapi yang melakukan pengukuran ini tidak mengetahui apakah pasien masuk kelompok satu atau kelompok dua.

\section{HASIL PENELITIAN}

Data yang dikumpulkan akan dianalisis dengan menggunakan bantuan software SPSS 11,5. Karena subyek tergolong bukan besar $(<30)$, maka sebaran data diasumsikan tidak berdistribusi normal, maka untuk uji beda dalam kelompok digunakan Wilcoxon test dan untuk antar kelompok digunakan Mann Whitney test. Tingkat kemaknaan ditetapkan 0,05.
Deskripsi karakteristik subjek penelitian berdasarkan umur dan indeks massa tubuh disajikan pada tabel di bawah ini.

\section{Tabel 1}

Karakteristik Subyek Penelitian Berdasar Umur dan jenis Kelamin

\begin{tabular}{lccccc}
\hline \multirow{2}{*}{$\begin{array}{c}\text { Karakteristik } \\
\text { Subjek }\end{array}$} & & $\begin{array}{c}\text { Jumlah } \\
\text { Kel 1 } \\
(\mathrm{n}=10)\end{array}$ & $\begin{array}{c}\text { Persentase } \\
\text { Kel 1 } \\
(\mathrm{n}=10)\end{array}$ & $\begin{array}{c}\text { Jumlah } \\
\text { Kel 2 } \\
(\mathrm{n}=10)\end{array}$ & $\begin{array}{c}\text { Persentase } \\
\text { Kel 2 } \\
(\mathrm{n}=10)\end{array}$ \\
\hline Umur & $51-55$ th & 5 & 50 & 2 & 20 \\
& $56-60$ th & 1 & 10 & 3 & 30 \\
& $61-65$ th & 1 & 10 & 2 & 20 \\
& 66-70 th & 3 & 30 & 3 & 30 \\
\hline Jenis kelamin & Laki laki & 6 & 60 & 8 & 80 \\
& Wanita & 4 & 40 & 2 & 20 \\
& & & & & \\
\end{tabular}

Tabel di atas menunjukkan bahwa semua subyek penelitian dapat dikategorikan sebagai insan lanjut usia dengan usia terbanyak adalah kelompok 5155 tahun. Sedangkan apabila dilihat dari jenis kelamin, maka mayoritas subyek penelitian adalah berjenis kelamin laki-laki.

Tabel 2

Karakteristik Subyek Penelitian Berdasarkan indeks massa tubuh (IMT)

\begin{tabular}{ccccc}
\hline & \multicolumn{4}{c}{ Jumlah dan Persentase } \\
\cline { 2 - 5 } Kategori & $\begin{array}{c}\text { Jumlah } \\
\text { Kel 1 } \\
(\mathrm{n}=10)\end{array}$ & $\begin{array}{c}\text { Persentase } \\
\text { Kel 1 }(\mathrm{n}=10)\end{array}$ & $\begin{array}{c}\text { Jumlah } \\
\text { Kel 2 } \\
(\mathrm{n}=10)\end{array}$ & $\begin{array}{c}\text { Persentase } \\
\text { Kel 2 } \\
(\mathrm{n}=10)\end{array}$ \\
\hline $\begin{array}{c}\text { Sangat kurus } \\
(<17)\end{array}$ & 0 & 0 & 1 & 10 \\
$\begin{array}{c}\text { Kurus } \\
(17-18,5)\end{array}$ & 1 & 10 & 2 & 20 \\
$\begin{array}{c}\text { Normal } \\
(18,5-25)\end{array}$ & 8 & 80 & 6 & 60 \\
$\begin{array}{c}\text { Gemuk } \\
(25-27)\end{array}$ & 1 & 10 & 1 & 10 \\
$\begin{array}{c}\text { Sangat } \\
\text { gemuk }(>27)\end{array}$ & 0 & 0 & 0 & 0 \\
\hline
\end{tabular}

Tabel di atas menunjukkan bahwa kebanyakan subyek penelitian memiliki indeks massa tubuh yang normal dan tidak ada yang mengalami kegemukan atau obesittas. 
Tabel 3

Data Skor Kapasitas Latihan pada Kelompok 1 dan 2 (Meter)

\begin{tabular}{lcccc}
\hline & \multicolumn{2}{c}{ Kelompok 1 } & \multicolumn{2}{c}{ Kelompok 2 } \\
\cline { 2 - 5 } & Pre & Post & Pre & Post \\
\hline Minimal & 257 & 302 & 192 & 317 \\
Maksimal & 297 & 357 & 298 & 363 \\
Range & 40 & 55 & 106 & 46 \\
Mean & 281 & 332,8 & 253,1 & 335,1 \\
SD & 12,76 & 19,08 & 41,87 & 16,27 \\
& & & & .
\end{tabular}

Sebelum tindakan terapi high intensity ground walking pada kelompok 1 reratanya adalah 281 meter, setelah perlakuan menjadi 332,8 meter. Sebelum tindakan latihan static bicycle pada kelompok 2 reratanya adalah 253,1 meter setelah perlakuan menjadi 335,1 meter. Terlihat adanya kenaikan kemampuan kapasitas latihan yang ditunjukkan dengan semakin jauhnya jarak tempuh saat melakukan tes jalan 6 menit.

Uji ini bertujuan untuk membandingkan skor kapasitas latihan sebelum perlakuan antara kelompok 1 dan kelompok 2. Analisis statistik menggunakan uji Mann Whitney $\mathrm{U}$, yang disajikan pada Tabel 4.

\section{Tabel 4}

\section{Hasil Uji Beda Kelompok 1 dam 2} Sebelum Perlakuan

\begin{tabular}{lcccc}
\hline Kelompok Subjek & $\mathrm{n}$ & Rerata \pm SD & $Z$ & $p$ \\
\hline Kelompok 1 & 10 & $281 \pm 12,76$ & & \\
Kelompok 2 & 10 & $253,1 \pm 41,87$ & $-0,984$ & 0,325 \\
& & & &
\end{tabular}

Tabel 4 di atas menunjukkan bahwa uji beda kapasitas latihan sebelum perlakuan pada ke dua kelompok pelatihan memiliki nilai $p=0,325(p>0,05)$. Hal ini berarti bahwa kedua kelompok sebelum perlakuan tidak ada perbedaan atau kedua kelompok berangkat dari keadaan kapasitas latihan yang sama.

Untuk mengetahui perbedaan rerata kapasitas latihan sebelum dan sesudah perlakuan pada kelompok 1 dan pada kelompok 2 digunakan uji Wilcoxon yang hasilnya tertera pada Tabel 5.

\section{Tabel 5}

Uji Beda Kapasitas Latihan Sebelum dan Sesudah Perlakuan Kelompok 1 dan 2

\begin{tabular}{lcccc}
\hline \multirow{2}{*}{ Kelompok } & \multicolumn{2}{c}{ Mean \pm SD } & & \multirow{2}{*}{$Z$} \\
\cline { 2 - 3 } & $\begin{array}{c}\text { Sebelum } \\
\text { Perlakuan }\end{array}$ & $\begin{array}{c}\text { Sesudah } \\
\text { Perlakuan }\end{array}$ & & $p$ \\
\hline Kelompok 1 & $281 \pm 12,76$ & $332,8 \pm 19,08$ & $-2,803$ & 0,005 \\
Kelompok 2 & $253,1 \pm 41,87$ & $335,1 \pm 16,27$ & $-2,803$ & 0,005 \\
\hline
\end{tabular}

Tabel 5 menunjukkan bahwa uji beda sebelum dan sesudah pelatihan pada masing-masing kelompok memiliki nilai $p$ $=0,005(\mathrm{p}<0,05)$. Hal ini berarti bahwa Ho ditolak dan Ha diterima, sehingga dapat dikatakan bahwa pada masing-masing kelompok terjadi peningkatan kapasitas latihan sesudah perlakuan dibandingkan sebelum perlakuan secara bermakna.

Uji beda ini bertujuan untuk membandingkan perbedaan rerata skor kapasitas latihan setelah perlakuan kelompok 1 dan kelompok 2. Analisis statistic menggunakan uji Mann Whitney $\mathrm{U}$, yang tersaji dalam table 6 berikut

Tabel 6

Hasil Uji Beda Kelompok 1 dan 2 Setelah Perlakuan

\begin{tabular}{ccccc}
\hline Kel & $\mathrm{n}$ & Mean \pm SD & $Z$ & $p$ \\
\hline Kel 1 & 10 & $332,8 \pm 19,07$ & & \\
Kel 2 & 10 & $335,1 \pm 16,27$ & $-0,38$ & 0,970
\end{tabular}


Berdasarkan hasil analisis dengan menggunakan uji Mann Whitney $U$, seperti pada Tabel 6 di atas, menunjukkan bahwa rerata kapasitas latihan sesudah perlakuan di antara kelompok 1dan 2 tidak terdapat perbedaan secara bermakna dimana nilai $p$ $=0,970(p>0,05)$. Hal ini berarti bahwa H0 diterima.

\section{PEMBAHASAN}

PPOM adalah merupakan penyakit pada sistem pernapasan dimana saluran pernapasan akan menyempit sehingga akan menghambat keluar masuknya udara ke paru yang akan menyebabkan keluhan sesak napas. Penurunan kapasitas latihan adalah merupakan problem utama yang dikeluhkan oleh penderita PPOM yang utamanya disebabkan oleh sesak pada saat melakukan aktivitas. Penurunan kapasitas latihan pada pasien PPOM bukan hanya akibat dari adanya kelainan obstruksi saluran nafas pada parunya saja tetapi juga akibat pengaruh beberapa faktor, salah satunya adalah penurunan fungsi otot skeletal yang berakibat penurunan aktivitas kehidupan sehari hari. Program rehabilitasi paru telah diketahui merupakan komponen yang penting dalam manajemen penderita PPOM dalam meningkatkan kapasitas latihan dan kualitas hidup (Lacasse et al, 2006; Ries et el, 2007). Salah satu jenis program rehabilitasi paru dalam meningkatkan kapasitas latihan dan kualitas hidup adalah latihan static bicycle. Latihan ini banyak digunakan di rumah sakit, mengingat jenis latihan ini dipandang efektif dan efisien terutama pada rumah sakit yang tidak memiliki lahan yang cukup untuk melakukan latihan seperti gimnasium. Disamping itu sepeda statis memiliki kelebihan banyak disukai pasien. Banyak pasien menganggap bahwa latihan dengan menggunakan sepeda statis akan memberikan keuntungan dibandingkan dengan latihan tanpa menggunakan alat, seperti latihan jalan. Jenis latihan ini adalah merupakan jenis latihan aerobik. Latihan aerobik adalah latihan yang memerlukan oksigen pada proses produksi energinya.Latihan aerobik umumnya dilakukan pada intensitas sedang dalam durasi waktu yang cukup panjang. Latihan aerobik akan meningkatkan konsumsi oksigen keseluruhan oleh tubuh sekaligus meningkatkan metabolisme tubuh.

Latihan aerobik yang dilaksanakan secara teratur dan terukur akan memberikan manfaat antara lain: (1) memperkuat otototot yang terlibat dalam respirasi, untuk memfasilitasi aliran udara masuk dan keluar dari paru-paru, (2) menguatkan dan memperbesar otot jantung, meningkatkan efisiensi memompa dan mengurangi denyut jantung istirahat, yang dikenal sebagai pengkondisian aerobik, (3) meningkatkan efisiensi sirkulasi dan mengurangi tekanan darah, (4) meningkatkan jumlah sel darah merah dalam tubuh, memfasilitasi transportasi oksigen, (5) meningkatkan kesehatan mental, termasuk mengurangi stres dan menurunkan kejadian depresi, serta peningkatan kapasitas kognitif, (6) mengurangi risiko untuk diabetes. Satu meta-analisis telah menunjukkan, dari beberapa penelitian yang dilakukan, bahwa latihan aerobik tidak membantu menurunkan $\mathrm{Hb}$ tingkat $\mathrm{A} 1 \mathrm{C}$ untuk diabetes tipe 2 (Snowling and Hopkins, 2006). 
Disamping itu, latihan aerobik juga memiliki keuntungan lain terhadap kinerja seperti : (1) meningkatkan penyimpanan molekul energi seperti lemak dan karbohidrat dalam otot, memungkinkan untuk meningkatkan daya tahan tubuh, (2) neovaskularisasi dari sarkomer otot untuk meningkatkan aliran darah melalui otot, (3) meningkatkan kecepatan di mana metabolisme aerobik diaktifkan dalam otot, yang memungkinkan sebagian besar energi untuk latihan intens yang akan dihasilkan aerobik, (4) meningkatkan kemampuan otot untuk menggunakan lemak selama latihan, menjaga glikogen otot, (5) meningkatkan kecepatan di mana otot-otot pulih dari latihan intensitas tinggi, (6) efek neurobiologis: perbaikan dalam hubungan struktural otak dan peningkatan kepadatan materi abu-abu, pertumbuhan neuron baru, fungsi kognitif ditingkatkan (kontrol kognitif dan berbagai bentuk memori), dan perbaikan atau perawatan kesehatan mental.

Hasil penelitian ini menunjukkan bahwa static bicycle exercise dapat meningkatkan toleransi aktivitas penderita PPOM yang diukur dengan menggunakan six minutes walking test secara siknifikan ( $\mathrm{p}$ $=0,005)$. Hasil penelitian ini didukung oleh beberapa penelitian yang meneliti tentang manfaat static bicycle exercise dalam meningkatkan toleransi aktivitas/kapasitas latihan dan kualitas hidup penderita PPOM (Casabuyi etal, 1991; Maltais etal, 2008).

Pada penelitian ini juga menghasilkan temuan bahwa High Intensity Ground Walking dapat meningkatkan kapasitas latihan pada penderita PPOM yang diukur dengan six minutes walking test secara siknifikan $(\mathrm{p}=0,005)$. Hasil penelitian ini juga didukung oleh hasil penelitian yang dilakukan oleh Hernandez et al., 2000) yang melakukan penelitian tentang manfaat latihan jalan dalam meningkatkan kapasitas latihan yang dilakukan selama 6 hari/minggu selama 12 minggu. Disamping itu penelitian yang dilakukan oleh Leung et al (2010) yang menemukan bahwa High Intensity Ground Walking dapat meningkatkan Kapasitas latihan penderita PPOM secara siknifikan setelah diberikan latihan selama 3 kali per minggu selama delapan minggu.

Namun demikian dari hasil analisis statistik tentang perbedaan dari kedua jenis latihan ini dalam meningkatkan kapasitas latihan ditemukan bahwa tidak ada perbedaan yang signifikan dari kedua jenis latihan tersebut $(\mathrm{p}=0,970)$. Hasil penelitian ini senada dengan penelitian yang dilakukan oleh Leung etal (2010) yang menemukan bahwa tidak ada perbedaan yang siknifikan antara latihan static bicycle dan high intensity ground walking dalam meningkatkan kapasitas latihan penderita PPOM, walaupun dalam penelitian tersebut jenis latihan high intensity ground walking sedikit lebih baik dalam meningkatkan kapasitas latihan dibandingkan dengan latihan static bicycle.

\section{KESIMPULAN DAN SARAN}

Kesimpulan dari penelitian ini adalah (1) Program latihan High Intensity Ground Walking meningkatkan kapasitas latihan pada penderita PPOM, (2) Program latihan Static Bicycle meningkatkan kapasitas latihan penderita PPOM, (3) Tidak ada perbedaan atau sama baik antara program latihan High Intensity Ground Walking 
dengan Latihan Static Bicycle dalam meningkatkan kapasitas latihan pada penderita PPOM.

Saran untuk mendapatkan hasil kesimpulan yang lebih komprehensif dan bisa dipercaya, maka perlu dilakukan penelitian lanjutan dengan subjek penelitian yang lebih banyak, pemakaian alat ukur lainnya yang lebih komprehensif, valid dan reliabel dan mengendalikan semua variabel pengganggu. Saran yang lain adalah untuk fisioterapis dan pasien agar dalam rehabillitasi pasien dengan penyakit PPOM agar menggunakan latihan peningkatan kapasitas latihan seperti berjalan dan static bicycle agar hasil rehabilitasi lebih komprehensif dan lebih optimal.

\section{DAFTAR RUJUKAN}

Celli, B.R.(2004). Standards for the Diagnosis and Treatment of Patients with Chronic Obstructive Pulmonary Disease. American Thoracic Society dan European Respiratory Society. New York.

Hui, KP and Hewitt, AB (2003). A simple rehabilitation program improve health outcome and reduces hospital utilization in patient with COPD. Chest; 124; 94-97.

Leung, RMW, Alison JA, McKeough ZJ, and Peters MJ (2010) Ground walk training improves functional exercise capacity more than cycle training in people with COPD: Randomized control tryal. Journal ofPhysiotherapy , 56: 105-112.

Ries, AL; Bauldoff GS, Carlin BW, Casaburi R, Emery CF, Mahler DA et al (2007) Pulmonary Rehabilitation: Joint ACCP/AACVPR Evidence-Based Clinical Practice Guidelines. Chest 131:4S-42S.

WHO (2012). Chronic Obstructive Pulmonary Disease. Diakses dari http://www.who.int/mediacentre. pada tanggal 10 Februari 2013. 